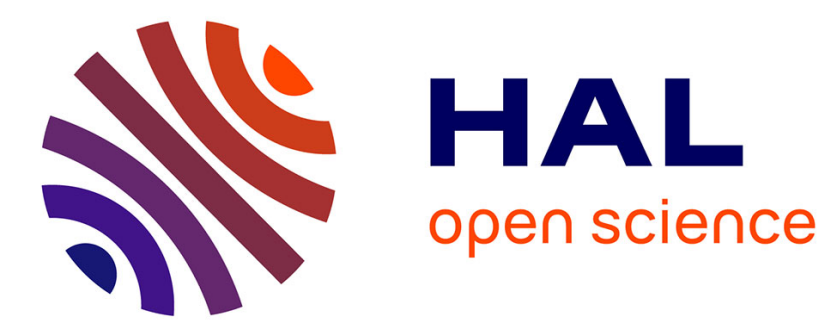

\title{
Open loop control of dielectrophoresis non contact manipulation.
}

Michaël Gauthier, Mohamed Kharboutly, Nicolas Chaillet

\section{To cite this version:}

Michaël Gauthier, Mohamed Kharboutly, Nicolas Chaillet. Open loop control of dielectrophoresis non contact manipulation.. International Symposium on Optomechatronic Technologies, ISOT'12., Oct 2012, Paris, France. 2 p. hal-00768453

\section{HAL Id: hal-00768453 \\ https://hal.science/hal-00768453}

Submitted on 21 Dec 2012

HAL is a multi-disciplinary open access archive for the deposit and dissemination of scientific research documents, whether they are published or not. The documents may come from teaching and research institutions in France or abroad, or from public or private research centers.
L'archive ouverte pluridisciplinaire HAL, est destinée au dépôt et à la diffusion de documents scientifiques de niveau recherche, publiés ou non, émanant des établissements d'enseignement et de recherche français ou étrangers, des laboratoires publics ou privés. 


\title{
Open loop control of dielectrophoresis non contact manipulation
}

\author{
Michaël Gauthier ${ }^{1}$, Mohamed Kharboutly ${ }^{1}$, Nicolas Chaillet $^{1}$,
}

\begin{abstract}
The framework of this paper is the study of "No Weight Robots-NWR" that use non-contact transmission of movement (e.g. dielectrophoresis) to manipulate micro-objects enabling significant throughput (1Hz). Dielectrophoresis (DEP) is currently used to separate, manipulate and detect micro particles in several domains with high speed and precision, such as in biological cell or Carbon Nano-Tubes (CNTs) manipulations. A dielectrophoresis system can also be considered as a robotic system whose inputs are the voltages of the electrodes and output is the object trajectory. This "No Weight Robots" enables the positionning of the manipulted object in a 3D space. This paper is summarized the modeling principle of this new type of robots and some first results on trajectory control in 2D space.
\end{abstract}

\section{INTRODUCTION}

The first industrial robot "UNIMATE" based on standard joints was commercialized in 1961 (see figure 1). Nowadays more than one million of robots are in use all over the world. In the 1980's the use of compliant structures in robotics was started to enable high precision positioning making them, at present, the most widely used structure for microscale robots. However, transmission of movement in such robots is obtained via the movements of mechanical parts which largely limits throughput due to inertial effects. In the 2000's, LightWeight Robots (LWR) have been developed to reduce robot inertia. However, the impact of inertia is still important.

Recently a new generation of robots that use non-contact transmission of movement to manipulate micro-objects is emerging. Besides eliminating the inertia of a robotic structure, this approach also eliminates friction and adhesion (between the tweezer and the component) which are highly detrimental to a robot performance and life time.

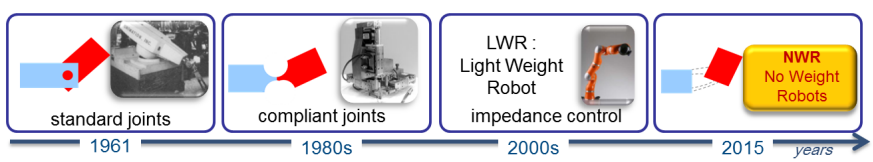

Fig. 1. History of the emergence of motion transmission in robotics: No Weight Robots - NWR is a new generation of robots based on non-contact motion transmission.

Current dielectrophoresis devices [1] are only open-loop controlled, such as the manipulation of particles [2], continuous separation and analysis of micro particles like biological cells and bacteria [3], dielectrophoretic fieldflow

1 FEMTO-ST Institute, AS2M dept. UMR CNRS 6174 UFC/ENSMM/UTBM, 24 rue Alain Savary, 25000, Besançon, France fractionation (DEP-FFF) separation [4], motion of carbon nanotubes [5]. Because of this open loop control, the objects trajectory and final position are not guaranteed. This paper summarizes our recent works on open loop control of microobject trajectory in a dielectrophoresis system.

\section{Direct Dynamic Model of A DIELECTROPHORESIS-BASED SYSTEM}

Usually, the inertia of micro-objects is negligible and the dynamic behavior of a micro-objet in a dielectrophoresis system is characterized by [6]:

$$
\overrightarrow{\dot{X}}=\left(\vec{F}_{D E P}(X, U)+\vec{P}\right) /(6 \pi \mu R),
$$

where:

$$
\vec{F}_{D E P}(X, U)=2 \pi \epsilon_{m} r^{3} \operatorname{Re}[K(\omega)] \nabla\left(\vec{E}^{2}(X, U)\right),
$$

where $K(\omega)$ is the Claussis-Mosoti factor, $\epsilon_{m}$ is the electrical permittivity fo the medium, $\vec{E}(X, U)$ the electric field and $\omega$ is the angular velocity of the electric field and $\mu$ the dynamic viscosity of the liquid. In order to compute this trajectory, a numerical simulator is needed. It must be able to compute the dielectrophoretic force generated by very complex geometries in function of the electrical tension $U$ on the electrodes. On the right hand, corresponding analytic equations are very complex and hard to establish. On the left hand, the finite element modeling (FEM) solution is limited by a long computation time and specially when electric voltage changes frequently. Thus, we propose to use the hybrid numeric simulator based on additive laws [6] combining the ability of the FEM solution to simulate complex electrode geometry and short computation time of analytical equations.

The diagram in figure 2 illustrates the $3 D$ direct dynamic modeling. Having the applied electric voltages and the electrodes geometry as input, the direct modeling simulator computes the micro-bead's corresponding trajectory. Generally,

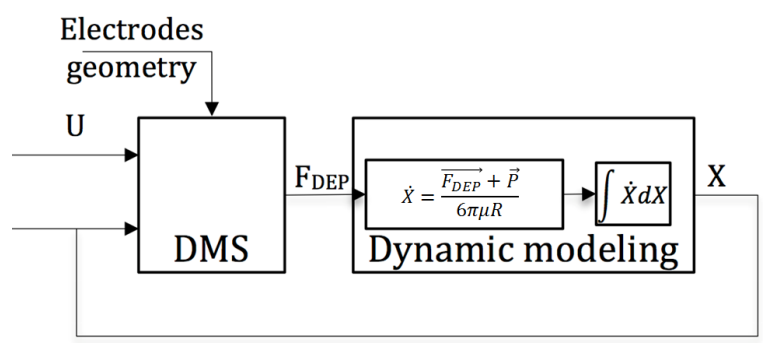

Fig. 2. A dynamic modeling and DMS are used to compute the microbead's 3D trajectory. 
the micro-bead's behavior in dielectrophoretic force field is characterized by its high dynamics and nonlinearity. This numeric simulator is experimentally validated in [6], [7] where we have shown that the dynamics are very high and the time response of the micro-bead is less than $3 \mathrm{~ms}$. Moreover the behavior of the micro-bead is subject to high nonlinearity and especially when the micro-bead approaches the electrodes.

\section{TRAJECTORY TRACKING}

To control the micro-bead's trajectory, an elementary control law for trajectories tracking has been established. The behavior of a micro-bead in a dielectrophoretic system is characterized by its high dynamics as presented in [6] and the nonlinearity with respect to the applied voltages as shown in the equation (1). This elementary control law must take into consideration this two problematics. Consequently a simple proportional integrator control is not sufficient especially when the micro-bead approaches the electrodes where the nonlinearity becomes very high. One way to solve this problem is to use the Newton-Raphson numeric method which is able to find the values of the control variables, $u_{x}$ and $u_{y}$ to follow a reference trajectory. By sampling the dynamic model (1) and knowing the trajectory $[\hat{x}(t), \hat{y}(t)]$ with respect to the time we are able to compute the appropriate control variable $u_{x}(t)$ and $u_{y}(t)$ using the Newton-Raphson method as illustrated in the figure 3.

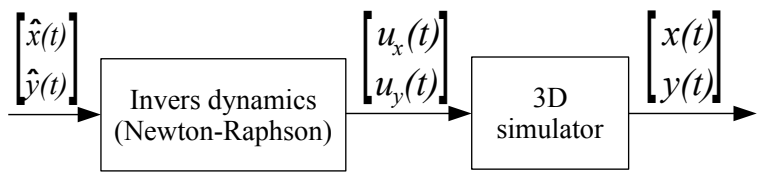

Fig. 3. The Newton-Raphson method is used to find the control variables $u_{x}$ and $u_{y}$

We have tracked a square reference trajectory with $1 \mathrm{~s}$ period, presented in the figure 4. Applying the NewtonRaphson method, a series of $u_{x}$ and $u_{y}$ control variables are computed and transmitted to a digital-analogic convertor to be applied to the electrodes (see figure 4). The position of the micro-bead (100 $\mathrm{m}$ diameter) is captured by a high speed camera acquisition at 300 images per seconds.

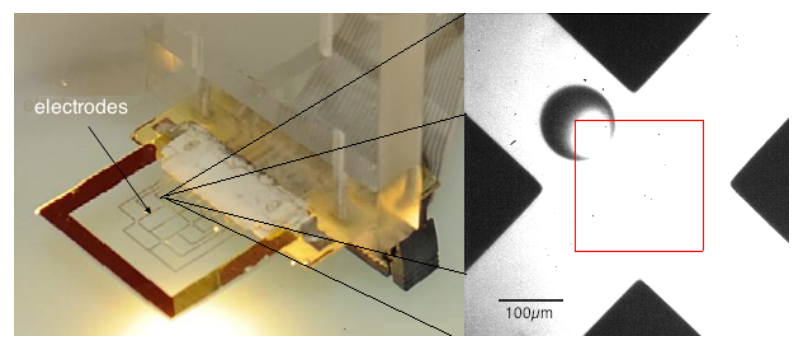

Fig. 4. Experimental electrode used to apply the dielectrophoretic motion. The square presents the reference trajectory.

The figure 5 shows the real trajectory of the micro-bead when applying the $u_{x}$ and $u_{y}$ series already computed. The relative error between the real trajectory and the reference is less then $8 \%$. This results shows the ability to control the trajectory of a micro-bead in dielectrophoretic system using open loop control strategy in a 2D space[8].

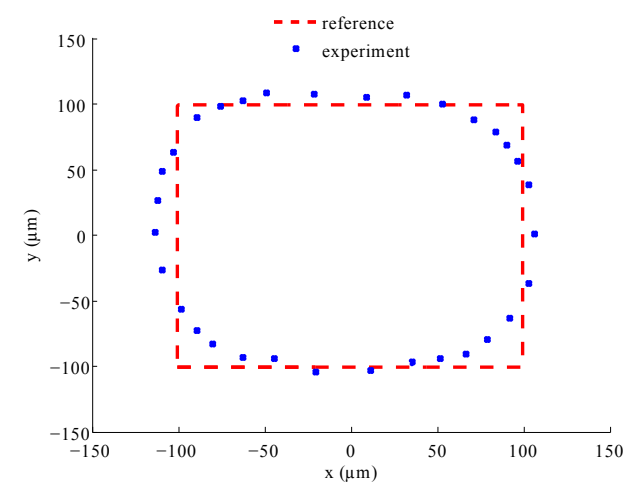

Fig. 5. The real trajectory of the micro-bead when applying the computed $u_{x}$ and $u_{y}$. The square is done in $1 s$.

\section{CONCLUSION}

In order to control the trajectory of a micro-object for long distance and high speed, an elementary open-loop positioning control for a micro-bead is presented using dielectrophoresis. A $3 D$ dielectrophoretic force simulator has been firstly presented. We have synthetised an 2D open loop control based on the non-linear inversion of the model. The approach has been validated experimentaly. This article shows the potentiality of non contact movement transmission in micro-nano-robotics using dielctrophoresis. Future works will focused on 3D control and closed loop control.

\section{ACKNOWLEDGMENT}

This work has been supported by the european project FAB2ASM (contract FoF-NMP-2010-260079).

\section{REFERENCES}

[1] R. Pethig, "Review article: Dielectrophoresis: Status of the theory, technology, and applications," Biomicrofluidics, vol. 4, no. 022811, 2010.

[2] T. Sun and H. Morgan, "Ac electrokinetic micro- and nano-particle manipulation and characterization," in Electrokinetics and Electrohydrodynamics in Microsystems, CISM Courses and Lectures, Springer, vol. . 530, pp. 1-28, 2011.

[3] R. Pethig, A. Menachery, S. Pells, and P. D. Sousa, "Dielectrophoresis: A review of applications for stem cell research," Journal of Biomedicine and Biotechnology, 2010.

[4] P. Gascoyne, "Isolation and characterization of celles by dielectrophoretic field-flow fractionation," In S. Kim, R. Williams, Karin, D. Caldwell Editors, Field-Flow Fractionation in Biopolymer Analysis, 2012.

[5] A. Kuzyk, "Dielectrophoresis at the nanoscale," electrophoresis, vol. 32, no. 17, pp. 2307-2313, September 2011.

[6] M. Kharboutly, M. Gauthier, and N. Chaillet, "Modeling the trajectory of a micro particle in a dielectrophoresis device." Journal of Appl. Phys., vol. 106, no. 11, pp. 114312 - 114312-7, 2009.

[7] M. Kharboutlyharboutly, M. Gauthierauthier, and N. Chaillet, "Modeling the trajectory of a micro particle in a dielectrophoresis device for dynamic control," in IEEE International Conference on Robotics and Automation ICRA'10, Anchorage, Alaska, USA, May 2010.

[8] M. Kharboutly, A. Melis, M. Gauthier, and N. Chaillet, "2d open loop trajectory control of a micro-object in a dielectrophoresis-based device," in In proc of the IEEE CASE, 2012. 